\title{
A interpretação dos sonhos no processo terapêutico
}

The interpretation of dreams in the therapeutic process

\section{Helena de Quadros Vicente e Cristina Adriana Rodrigues Kern ${ }^{2}$}

Resumo: Os autores destacam a forte presença do sonho na psicanálise, desde Freud. Inicia-se o trabalho revisitando uma das obras mais importantes de Freud, texto fundante da psicanálise, "A interpretação dos sonhos", apresentando um resumo das ideias principais sobre o processo onírico. Buscamos, por meio de revisão de literatura, autores com ideias próprias sobre sonhos, sonhar e trabalho clínico com sonhos, tentando verificar a invariância com as proposições freudianas, assim como extensões e desenvolvimentos da teoria. Apresentam-se, ainda, exemplos clínicos do sonho como importantes fatores de comunicação entre analista e analisando, fazendo um esclarecimento de como o analista pode trabalhar os sonhos e como estes se apresentam dentro do setting terapêutico. Deste modo, os sonhos podem ser vistos como ferramentas de acesso ao inconsciente através de métodos propostos por Freud e de formas particulares posteriormente desenvolvidas por outros autores, sendo possível compreender o papel dos mesmos na psique e enfatizar os motivos pelos quais os psicólogos devem considerar os sonhos no fazer da sua profissão.

Palavras-chave: Psicanálise; Sonhos; Interpretação dos sonhos.
Abstract: The authors highlighted the strong presence of dreams in psychoanalysis since Freud. They begin by revisiting one of Freud's most important works, the founding text of psychoanalysis, "The interpretation of dreams", presenting a summary of the main ideas about the dream process. Through literature review, they seek authors with their own ideas about dreams, dreaming and clinical work with dreams, trying to verify the invariance with Freudian propositions, as well as extensions and developments of the theory. Clinical examples of the dream are also presented as important communication factors between the analyst and the analysand, clarifying how the analyst can work with dreams and how they present themselves within the therapeutic setting, and can be seen as tools for accessing the unconscious through methods proposed by Freud and in particular ways later developed by other authors, making it possible to understand the role of dreams in the psyche and to emphasize the reasons why psychologists should consider dreams in the making of their profession.

Keywords: Psychoanalysis; Dreams; Interpretation of dreams.

\footnotetext{
1 Estudante do curso de Psicologia da Universidade do Extremo Sul Catarinense - Criciúma/SC. E-mail: lenabqv@gmail.com

2 Mestre em Psicologia Clínica pela Universidade do Extremo Sul Catarinense. Professora no curso de Psicologia na Universidade do Extremo Sul Catarinense - Criciúma/SC. E-mail: cristinak@unesc.net
} 


\section{Introdução}

Em 1900, Freud publica seu livro denominado "A Interpretação dos Sonhos"e, na presente obra, formula uma nova visão sobre os significados dos sonhos. Trata-se de uma obra revolucionária que reformula a forma de compreender o mundo onírico. Esse trabalho apresenta uma grande descoberta de Freud: "0 sonho pode ser interpretado, e sua interpretação mostra que ele consiste em uma realização de desejo." (Rivera, 2017, p. 17).

$\mathrm{Na}$ atualidade, autores revisam as concepções de Freud acerca dos sonhos; alguns fortalecem as suas proposições, outros propõem integrar conhecimentos como, por exemplo, das neurociências aos saberes psicanalíticos. Estas contribuições ocorrem em função de eminentes psicanalistas.

Freud concebeu a teoria dos sonhos como resultado de desejos inconscientes, por vezes proibidos que, por conta do seu conteúdo, acabaram por sofrer repressão. Esses conteúdos reprimidos retornam à consciência através do trabalho onírico que funciona como um filtro para que essas imagens retornem de alguma forma, a fim de satisfazer o desejo latente, mesmo que através de distorçōes, retornando como forma de imagens dentro dos sonhos (Rivera, 2017).

Da descoberta de Freud, em 1900, aos dias de hoje, centenas de colegas sedebruçaram sobreo inquietantetema, valorizaram suas observações, partilharam suas ideias, e nos permitem perceber que a psicanálise contemporânea oferece um proficuo instrumental para que possamos acolher e trabalhar os sonhos e o sonhar, em nossas salas de análise. Outra construção, não menos significativa, ocorreu nestes anos de trabalho, dentro de cada um de nós (Perrini, 2017, p. 68).

Diante desse panorama, 0 trabalho proposto procura compreender 0 mundo onírico, a fim de enfatizar a sua importância no processo terapêutico, a partir de Freud e de estudos atuais.

\section{Método}

0 presente artigo trata-se de uma revisão bibliográfica sobre a temática da interpretação dos sonhos. A revisão, de acordo com Gil (2008), refere-se a uma pesquisa desenvolvida a partir de material elaborado previamente, por meio de livros e artigos.

Para a construção deste trabalho, foram utilizados textos clássicos da obra freudiana, além de livros que abordassem a temática proposta em língua portuguesa. Além disso, foram pesquisados artigos científicos, publicados em periódicos indexados nas bases de dados Scielo, Lilacs e Pepsic, com as palavras chave: "interpretação dos sonhos" e "sonhos no processo terapêutico", priorizando artigos dos últimos cinco anos. A pesquisa foi motivada a fim de reunir contribuições atuais sobre o tema. Esse tipo de pesquisa tem como objetivo "0 aprimoramento de ideias ou descoberta de intuições." (Gil, 2002, p. 42).

\section{A interpretação dos sonhos de 1900}

Freud foi pioneiro ao dar uma dimensão científica quanto à compreensão da formação e das funções dos sonhos, além do entendimento dos seus signi- ficados inconscientes e recomendações técnicas. "A interpretação dos sonhos" datada de 1900, é a primeira obra propriamente psicanalítica de Freud. No capítulo VII, especialmente, se encontra uma teoria geral do aparelho psíquico, a partir dos estudos de Freud sobre os sonhos, que eram, segundo ele, a"via régia de acesso ao conhecimento do inconsciente na vida mental" (p. 43). Desde então, assim como mudou a compreensão da gênese e o significado dos sintomas e atos-sintomas, repensando-se a origem, formação, decodificação, compreensão do simbolismo e dos significados, também a interpretação dos sonhos sofreu substanciais mudanças (Zimerman, 2004).

Em síntese, pode-se dizer que Freud concebeu o fenômeno dos sonhos como resultante de inconscientes desejos infantis, às vezes proibitivos e que, portanto, foram reprimidos, constituindo o "conteúdo latente". 0 retorno à consciência seria sob a forma de "conteúdo manifesto", forma de gratificação dos desejos, após serem mobilizados por algum "resto diurno", terem a permissão da "censura onírica" e sofrerem a ação do "trabalho onírico". Assim, por meio de distorções que disfarçam os desejos, se manifestam a partir da gratificação alucinatória, com imagens visuais (Zimerman, 2004).

O sonho, portanto, "não é um fenômeno acessório ou aleatório, mas um importante e complexo trabalho psíquico" (Rivera, 2017, p. 17). Por trás do desejo, imagens são distorcidas e disfarçadas a fim de vencer a censura psíquica que se opõeà manifestação do verdadeiro significado do desejo. Rivera (2017, p. 18) traz que"o método freudiano consiste simplesmente em fazer com que 0 sonhador fale sobre o sonho". A ferramenta da psicanálise, de associação livre, que propõe ao paciente que fale tudo que Ihe remeter à cabeça, a fim de dar ao psicanalista dados riquíssimos sobre o inconsciente do seu paciente, pode ser usada também no momento em que o paciente se dispõe a contar um sonho. Cada sonho traz consigo uma abertura inédita acerca do inconsciente do sonhador, que o psicanalista, ao explorá-lo no trabalho interpretativo, consegue desmembrar e dar sequência ao processo de conhecer o seu paciente e fazer com que ele conheça a si mesmo (Rivera, 2017).

Para Freud, a interpretação dos sonhos era considerada como o mais firme pilar da teoria psicanalítica. Desde cedo Freud se interessava pelos sonhos, pois costumava sonhar muito. Iniciou com o propósito de escrever um livro em maio de 1897, "pouco antes de iniciar o que ele chama de "autoanálise", realizada por meio da interpretação de seus próprios sonhos" (Rivera, 2017, p. 20). Em julho de 1897 começou a relatar seus sonhos a Fliess através do envio de cartas. Podemos considerar Fliess um grande amigo de Freud, e que nesse período assumiu um papel próximo ao papel de analista para ele.

Freud, ligando os sonhos ao estudo de psicopatologias diz que "quem não souber explicar a origem das imagens oníricas também se esforçará em vão por compreender as fobias, as ideias obsessivas e delirantes, e, eventualmente, exercer uma influência terapêutica sobre elas" (Freud, 2017, p. 3).

Na visão freudiana, todos os sonhos podem ser interpretados utilizando algumas técnicas para esse fim e, se utilizadas de maneira correta, "todo sonho se mostra como uma formação psíquica de pleno sentido que pode ser incluída num ponto determinável da atividade psíquica do estado de vigília" (Freud, 2017, p. 15).

Podemos dizer, seguindo os estudos de Freud que, em certos sonhos utiliza-se de momentos da infância, momentos estes que não nos lembramos nem utilizamos mais em estado de vigília, para reproduzir as imagens oníricas. Hildebrandt (1875, p. 23, como citado por Freud 1933, p. 30) diz que "já foi admitido de maneira expressa que às vezes o sonho traz fielmente de volta 
à nossa psique, com espantosa capacidade de reprodução, acontecimentos distantes e mesmo esquecidos das épocas mais remotas". Sobre isso Valkelt (1875, p. 119 apud Freud, 2017, p. 30) diz que "é digno de nota a facilidade com que recordações da infância e da juventude tomam partes dos nossos sonhos. 0 sonho nos lembra sem descanso de coisas em que há muito tempo não pensamos mais (...) que já perderam toda importância para nós".

Freud traz em seu trabalho diversos questionamentos acerca do sentido dos sonhos. Se pergunta se todos os sonhos são, de fato, realizações de desejos, ou se cada sonho possui sentidos diferentes. 0 que nos confunde é que, se os sonhos são realizações de desejos, de onde emergem as figuras estranhas e descontextualizadas que são utilizadas para expressar esse fim? Freud escreve que "mesmo se estivermos preparados para o fato de todo sonho ter um sentido e um valor psíquico, ainda precisamos deixar aberta a possibilidade de que esse sentido não seja o mesmo para todos os sonhos" (Freud, 2017, p. 144).

Existe, dentro da teoria dos sonhos de Freud, a teoria que se denomina como sonhos de comodidade e Freud exemplifica bem ao nos remeter aos sonhos de saciar a sede tomando água. Trata-se de sonhar em estar satisfazendo a vontade de beber água e, ao despertar, o sujeito acorda sedento e toma água de fato, ou seja, através do sonho esse desejo de beber água já foi satisfeito, mas como se trata de uma necessidade biológica, não se satisfaz por completo através do sonhar. Um exemplo de sonho pessoal de Freud é usado para fortalecer a teoria:

Fiquei com sede antes de adormecer e esvaziei o copo que fica sobre a mesinha de cabeceira ao lado da minha cama. Algumas horas depois, sobreveio um novo acesso de sede, acompanhado de seus desconfortos. Para conseguir água, eu teria de me levantar e pegar o copo que está sobre a mesinha de cabeceira de minha mulher. Sonhei, apropriadamente, que minha mulher me dava de beber de um recipiente; esse recipiente era uma urna etrusca que eu trouxera de uma viagem à Itália e que mais tarde dei de presente a alguém. Contudo, a água dessa urna tinha um gosto tão salgado (das cinzas, é evidente) que precisei acordar. (Freud, 2017, p. 145).

Freud destaca que a urna em questão foi dada a alguém e que inconscientemente ele lamenta não ter mais esse objeto, o mesmo ocorreu com 0 copo d'água, que também não era acessível. Com relação ao gosto salgado, Freud interpreta que a razão desse sabor teria sido atribuída para que ele fosse obrigado a acordar e satisfazer esse desejo em estado de vigília. Percebemos então que o sonho sempre busca conseguir o que almeja de maneira cômoda, sendo que o único objetivo é a satisfação do desejo, como no sonho de Freud. Dessa forma, podemos ver o quanto o sonho pode ser egoísta, "0 amor à comodidade de fato não é compatível com a consideração pelos outros" (Freud, 2017, p. 145).

Um amigo de Freud relatou o sonho de sua esposa, "minha mulher pediu que lhe contasse que ontem ela sonhou que tinha menstruado", Freud e sua capacidade sublime de interpretação retornou o relato indagando "você deve saber o que isso significa". Interpretou "se a jovem sonhou que tinha menstruado, foi porque a menstruação não veio. Posso imaginar que ela teria apreciado sua liberdade por mais algum tempo antes que começasse as fadigas da maternidade" (Freud, 2017, p. 147). Outra interpretação com esse tema foi quando um amigo lhe contou que sua esposa sonhou que sua blusa estava com manchas de leite, nesse caso Freud interpreta sendo, não somente 0 anúncio de uma nova gravidez, mas também que "a jovem mãe deseja ter mais alimento para o segundo filho do que teve para o primeiro" (Freud, 2017, p. 147).

Com essa sequência de exemplos, é possível identificar que os sonhos como realizações de desejos são bastante comuns e exibem seu objetivo sem rodeios. Na maioria das vezes esses sonhos são curtos e simples segundo Freud (2017), mas de qualquer forma vale a pena investigá-los melhor. Sonhos curtos e simples também são encontrados frequentemente nas crianças, pois estas não possuem produções oníricas tão complexas quanto os adultos.

A filha de Freud teve um sonho simples de realização de desejo. Ela então com três anos na época foi com a família visitar um lago de Aussee, na Áustria. Durante o passeio, eles atravessaram o lago e a viagem passou depressa, quando chegou o momento de deixar o barco, a menina chorou muito e não quis desembarcar. Na manhã seguinte, Freud $(1933$, p. 150) conta que a menina relatou "essa noite eu passeei no lago", com isso, Freud constata que "esperemos que a duração da viagem onírica a tenha deixado mais satisfeita".

A investigação de que os sonhos são realizações de desejos não começou por Freud, mas vem desde 1879 sendo pensada por outros autores. Freud (1933, p. 155) diz que"não devam existir outros sonhos além dos sonhos de cumprimento de desejo é uma generalização ilegítima, felizmente fácil de refutar". Isto porque há inúmeros sonhos com conteúdos desagradáveis que facilmente questionam essa teoria. Além dos sonhos desagradáveis, existem os sonhos de angústia, "em que a mais horrenda das sensações de desprazer nos sacode até acordarmos, e são justamente as crianças, nas quais o senhor encontrou sonhos de desejo sem disfarces, que são atormentadas por eles com mais facilidade" (Debacker, 1881, apud Freud, 2017, p. 156).

Os sonhos de angústia, de acordo com Freud (1933) quase tornam a teoria dos sonhos como realização de desejos como algo absurdo, entretanto, Freud se esquiva desse argumento.

É necessário apenas observar o fato de que minha teoria não se baseia numa consideração do conteúdo manifesto dos sonhos, mas se refere aos pensamentos que o trabalho de interpretação mostra estarem por trás dos sonhos. Devemos estabelecer um contraste entre os conteúdos manifesto e latente dos sonhos. Não há dúvida de que existem sonhos cujo conteúdo manifesto é de natureza extremamente aflitiva. Mas terá alguém tentado interpretar esses sonhos? Revelar os pensamentos latentes que se encontram por trás deles? Se não for assim, as duas objeções levantadas contra minha teoria são inconsistentes: é ainda possível que os sonhos aflitivos e os sonhos de angústia, uma vez interpretados, revelem-se como realizações de desejos (Freud, 2017, p. 156).

Com isso, o questionamento não se baseia apenas em como os sonhos desagradáveis e os sonhos de angústia podem ser realizações de desejo, mas também podemos questionar o motivo pelo qual os sonhos de conteúdo indiferente não mostram o seu sentido verdadeiro. 
Em 1895, Freud tratou psicanaliticamente uma paciente ligada à sua família. Pelo fato de tratar alguém tão próximo, Freud teve algumas inseguranças, pois qualquer fracasso poderia influenciar os laços de amizade entre eles. "0 tratamento teve êxito parcial, a paciente perdeu a sua angústia histérica, mas não todos os seus sintomas somáticos" (Freud, 2017, p. 127). No momento do tratamento, Freud ainda não sabia exatamente quais os critérios que proporcionariam desvinculação total do histórico clínico de histeria, e exigiu da paciente uma solução que não foi muito aceita. Com isso, interromperam o tratamento com a chegada do verão. Um dia, Freud recebeu uma visita de um colega mais jovem que já havia visitado a paciente Irma, "perguntei-Ihe como a encontrara, e recebi a resposta de que ela estava melhor, mas não inteiramente boa (Freud, 2017, p. 127). Freud se incomodou com essa resposta, e interpretou-a como uma tentativa de censura, como se esse colega o estivesse cobrando porque ele havia prometido demais à paciente. "Atribuí a suposta tomada de partido de 0tto contra mim à influência dos familiares da paciente, que, como supunha, nunca tinham visto meu tratamento com bons olhos"(Freud, 2017, p. 127). Na mesma noite em que recebeu a visita do seu colega 0tto, Freud redigiu o histórico clínico de Irma, parecido mais como uma autojustificação, e repassou ao dr. M., que na época "era a personalidade que dava o tom em nosso círculo" (Freud, 2017, p. 127). Nessa mesma noite, Freud teve um sonho que anotou assim que acordou no outro dia:

Um grande salão - numerosos convidados a quem estávamos recebendo. - Entre eles estava Irma. No mesmo instante, puxei-a de lado, como que para responder a sua carta e repreendê-la por não ter ainda aceitado minha "solução". Disse-Ihe:" "Se vocêainda sente dores, é realmente apenas por culpa sua." Respondeu ela:"Ah! se 0 senhor pudesse imaginar as dores que sinto agora na garganta, no estômago e no abdômen. . . - isto está me sufocando." - Fiquei alarmado e olhei para ela. Parecia pálida e inchada. Pensei comigo mesmo que, afinal de contas, devia estar deixando de perceber algum distúrbio orgânico. Levei-a atéa janela e examinei-lhe a garganta, e ela deu mostras deresistências, como fazem as mulheres com dentaduras postiças. Pensei comigo mesmo que realmente não havia necessidade de ela fazer aquilo. - Em seguida, ela abriu a boca como devia e, no lado direito, descobri uma grande placa branca; em outro lugar, vi extensas crostas cinza-esbranquiçadas sobre algumas notáveis estruturas recurvadas, que tinham evidentemente por modelo os ossos turbinados do nariz. - Chamei imediatamente 0 Dr. M., e ele repetiu o exame e o confirmou. . . 0 Dr. M. tinha uma aparência muito diferente do habitual; estava muito pálido, manca , está sem barba no queixo... Meu amigo Otto estava também agora de pé ao lado dela, e meu amigo Leopold a auscultava através do corpete e dizia: "Ela tem uma área surda bem embaixo, à esquerda." Indicou também que parte da pele do ombro esquerdo estava infiltrada. (Notei isso, tal como ele fizera, apenas do vestido.) ... M. disse: "Não há dúvida de que é uma infecção, mas não tem importância; sobrevirá uma disenteria, e a toxina será eliminada." .. . Tivemos também pronta consciência da origem da infecção. Não muito antes, quando ela não estava se sentindo bem, meu amigo Otto Ihe aplicara uma injeção de um preparado de propil, propilos. . . ácido propiônico . . trimetilamina (e eu via diante de mim a fórmula desse preparado, impressa em grossos caracteres)... Injeções como essas não deveriam ser aplicadas de forma tão impensada . . . E, provavelmente, a seringa não estava limpa. (Freud, 2017, p. 128).

Para Freud, a interpretação desse sonho ficou bastante clara, tendo em vista os acontecimentos do dia anterior. A notícia que recebeu de seu colega e, também, por ter ficado escrevendo até tarde a respeito do caso de Irma ocuparam não só o estado de vigília, como também preencheram a atividade psíquica durante o sono. Freud se dedicou a fazer uma análise minuciosa do seu sonho. A começar pelo salão, Freud passava o verão em Bellevue, diz que "essa casa fora no passado destinada a ser um estabelecimento de recreio, daí os cômodos extraordinariamente altos e em forma de salão" (Freud, 2017, p. 129). 0 sonho ocorreu poucos dias antes do aniversário de sua esposa, que havia, durante o dia, manifestado expectativas com relação aos convidados que viriam ao seu aniversário, entre eles também Irma.

Na parte em que Freud censura Irma por não ter aceitado a solução proposta por ele, e que a culpa pelo insucesso do seu tratamento era somente dela, Destaca:"naquela época, minha opinião era de que minha tarefa se limitava a comunicar ao paciente o sentido oculto de seus sintomas" (Freud, 2017, p. 130). Com isso, o fato de a paciente não aceitar a solução proposta por Freud, solução esta que seria a cura dos problemas dela, não era mais responsabilidade dele. Na frase em que ele censura Irma no sonho, se traduz o fato de que ele não queria carregar essa culpa por ela ainda sentir dores, no momento em que ele culpa a paciente, projeta a culpa nela e a culpa consequentemente deixa de ser dele.

Sobre as queixas de Irma, Freud diz que só conhecia os problemas que ela tinha de estômago, e que esses problemas não eram assim tão relevantes, "fico surpreso por ter escolhido esses sintomas no sonho, e por enquanto também não conheço os motivos." (Freud, 2017, p. 130). No sonho, quando menciona o fato de ela estar pálida e inchada é o oposto da paciente em estado de vigília, que estava sempre corada, com isso Freud (1933, p. 130) supõe que outra pessoa substituiu a paciente no sonho. Sobre as dores de Irma serem desencadeadas por fatores orgânicos, Freud atribui a isso que, "se as dores de Irma têm um fundamento orgânico, então não tenho obrigação de curá-la, afinal meu tratamento elimina apenas dores histéricas. Parece-me, portanto, que eu desejaria um erro de diagnóstico, então a censura pelo fracasso também estaria eliminada" (Freud, 2017, p. 131).

Esse sonho de Freud segue o questionamento do porquê que os sonhos não mostram o que querem dizer de maneira objetiva. "Na realidade, também o sonho da injeção de Irma não dá, de início, a impressão de figurar o cumprimento de um desejo do sonhador" (Freud, 2017, p. 157). Freud diz também, que sem a interpretação, não saberia dizer se foi, de fato, a realização de um desejo seu. Agora nasce outro questionamento: Qual a origem da distorção dos sonhos?

Freud traz outro sonho pessoal para responder ao questionamento da origem da distorção dos sonhos. Esse sonho se sucedeu quando Freud soube 
que dois professores da universidade sugeriram seu nome para ser nomeado ao cargo de professor adjunto e, com isso, criou bastante expectativa e ficou muito feliz ao saber que dois grandes nomes o reconheceram dessa maneira. Em uma tarde, Freud recebeu a visita de um colega que já havia se candidatado à vaga em questão: "contou-me que dessa vez tinha colocado 0 alto senhor contra a parede e the perguntado com franqueza se 0 adiamento da sua nomeação realmente se devia a motivos confessionais" (Freud, 2017, p. 158). A resposta que seu colega obteve foi "sem dúvida, considerando a tendência atual, Sua Excelência não estava em condições no momento etc" (Freud, 2017, p. 158). Com isso, Freud teve suas expectativas diminuídas, pois acreditava que os mesmos motivos confessionais também eram aplicáveis a ele.

Na madrugada desse dia, Freud teve um sonho e os pontos principais do seu sonho foram, no primeiro momento, sonhar com um amigo que ele chama de R. (que ao mesmo tempo era seu tio) e expressar grande ternura pelo mesmo. Depois observou que o rosto dele estava um pouco modificado, "como se tivesse sido esticado, e uma barba amarela que o cobre se destaca com especial nitidez" (Freud, 2017, p. 159).

$\mathrm{Na}$ interpretação, Freud teve bastante dificuldade, teve que diversas vezes se censurar para conseguir fazê-la, pois só conseguia observar o quão absurdo este fora. Se R., no sonho, era seu tio, observou que teve apenas um tio, chamado Josef, que acabou sendo punido pela lei por fazer coisas ilícitas, que Freud ligou esse fato a sua ganância. 0 pai de Freud sempre dizia que esse tio era "um imbecil". Sobre as características da barba, Freud relembra que o rosto do tio Josef"era de fato assim, alongado, coberto por uma bela barba loura" (Freud, 2017, p. 160). Entretanto, seu amigo R. tinha cabelos pretos, mas a isso fez uma menção às características da barba no processo de envelhecimento:

um a um, os fios pretos da barba passam por uma desagradável mudança de cor; primeiro ganham um tom castanho-avermelhado, depois castanho-amarelado e só então ficam definitivamente grisalhos. É nesse estágio que se encontra a barba do meu amigo R. (...) 0 rosto que vejo no sonho é ao mesmo tempo o do meu amigo R. e o de meu tio (...) Portanto, não há qualquer dúvida de que realmente penso que meu amigo R. é um imbecil - tal como meu tio Josef (Freud, 2017, p. 160).

Freud, para finalizar a interpretação da ligação do seu tio Josef a seu amigo R. menciona um diálogo que teve com outro amigo, N. que também fora indicado ao cargo de professor. Entretanto $\mathrm{N}$. Ihe contou que foi acusado por uma moça, que a acusação havia sido suspensa, porém acreditava que isso era suficiente para não ser nomeado. Era a peça que faltava a Freud para entender a figura de seu tio no sonho: "meu tio Josef figura os dois colegas que não foram nomeados professores, um deles como imbecil e o outro como criminoso"(Freud, 2017, p. 161). Ainda, com relação a sua expectativa quanto ao cargo, Freud interpreta:

se motivos confessionais são determinantes para 0 adiamento da nomeação de meus amigos R. e N., então a minha nomeação também é posta em questão; no entanto, se posso atribuir a rejeição de ambos a outras razões, que não me atingem, minha esperança não é perturbada. Esse é o procedimento do meu sonho; ele transforma um deles, R., em imbecil, e o outro, N., em criminoso; mas não sou uma coisa nem outra; nada temos em comum, devo esperar pela minha nomeação ao cargo de professor (...) (Freud, 2017, p. 161).

Depois de Freud dar-se conta de que, no sonho, expressa grande ternura ao seu amigo (e tio) R., questionou-se de onde saiu tamanho sentimento:

naturalmente, nunca tive sentimentos ternos pelo meu tio Josef. Meu amigo R. me é caro e estimado há anos; porém, se me dirigisse a palavra a ele e expressasse minha afeição em palavras que correspondessem mais ou menos ao grau de minha ternura no sonho, ele sem dúvida ficaria assombrado (Freud, 2017, p. 162).

Ele observou essa ternura como sendo "falsa e exagerada, da mesma forma que meu juízo sobre suas qualidades intelectuais, o qual expresso fundir sua personalidade com a de meu tio; porém ela é exagerada no sentido contrário" (Freud, 2017, p. 162). Freud interpreta a ternura como não pertencente aos pensamentos que estão por trás do sonho, mas sim em oposição a esses pensamentos, com o objetivo de "ocultar o conhecimento obtido com a interpretação do sonho" (Freud, 2017, p. 162). Quanto a isso, Freud relembra 0 quanto foi difícil fazer a interpretação desse sonho, reconhece a sua resistência, e descobre a sua tentativa de recalcar esse sentimento. Freud desvenda 0 motivo da sua resistência,"era a afirmação de que R. é um imbecil. Não posso atribuir a ternura que sinto por R. aos pensamentos oníricos latentes, mas a essa minha resistência" (Freud, 2017, p. 162). Os pensamentos oníricos de Freud acerca de R. contêm um insulto, então para que ele não se desse conta disso, a ternura vem para dissimular esse pensamento.

Com isso, podemos compreender que quando não reconhecemos no sonho a realização do desejo, podemos pensar que houve uma tendência à defesa contra o reconhecimento desse desejo, então a única forma desse desejo se manifestar é através da distorção.

\section{Algumas perspectivas atuais sobre o campo (analítico) do sonhar}

A partir da revisão na base de dados, poucos artigos atuais foram encontrados. Supõe- se que a destinação deste tipo de escrita se concentre a revistas específicas da área de psicanálise. Os trabalhos encontrados se engendram na obra Freudiana e trazem contribuições sobre o uso dos sonhos como dispositivo no processo terapêutico, por meio de revisão de literatura e de relato e discussão de casos.

Foster (2017) apresenta situações clínicas que justificam a continuação da interpretação dos sonhos noturnos, tal qual proposta por Freud (2017), utilizando o método da associação livre de ideias, sinônimo da regra fundamental. A autora observa que em nossos meios essa forma de escutar 0 sonho noturno tem sido substituída por outro método e justifica sua proposta alegando que, em sua experiência, a interpretação de sonhos realizada dentro dessa abordagem possibilita o desenvolvimento da escuta psicanalítica. Além disso, entende que "aspectos primitivos do mundo mental do paciente podem emergir em sala de análise, recebendo um maior acolhimento pelo 
paciente, trazendo maior percepção da complexidade de seu mundo mental e ampliando seu interesse em ser apresentado a si mesmo" (Foster, 2017, p.97).

A autora defende que "para que a interpretação dos sonhos seja possível, necessitaremos (SEGUE PARÁGRAFO RETIRADO DO ARTIGO PARA A CONFERÊNCIA) da colaboração do paciente com suas associações livres de ideias. Essas associações é que se tornarão a via régia para o inconsciente" (Foster, 2017, p. 99). Ademais, os personagens e cenários criados no mundo onírico do paciente devem ser associados pelo autor do sonho, nunca pelo analista, Bion (1985, p. 129 apud Foster, 2017, p. 100) diz que "minhas associações livres guardei-as para mim, mesmo porque se supõe que seja eu 0 analista".

\section{Se o paciente nada associa e não conseguimos 0 estímulo neces-} sário para que suas defesas baixem e ele possa colaborar nesse processo, não temos senão a percepção de que estamos diante de resistências, e nosso legado é continuar investigando. Algumas poucas vezes, em minha experiência, o paciente comunica aquele sonho ou outro sonho de outrora, também de forma associativa com algo que estamos vivenciando, e nessas situações observo que se autoriza a associar (Foster, 2017, p. 100).

A autora sugere ainda, com base nos escritos de Freud, que 0 analista deve questionar os elementos do sonho e ao que o paciente interliga esses elementos, a fim de acessar a essência do que não foi descoberto de imediato, a isso denomina como "sonhar o sonho do paciente".

Sobre o método de análise de sonhos através da técnica de associação livre, Foster (2017, p. 102) conclui que"0 que tenho observado é que os pacientes ficam mais interessados em seus sonhos e em sua complexa estrutura psíquica, e mais estimulados com o próprio processo da análise, por serem apresentados a si mesmos." A autora ainda complementa "sem essa valiosa ferramenta de trabalho, esses aspectos levariam muito tempo para aparecer, devido às resistências às quais estamos expostos" (Foster, 2017, p. 105).

Foster (2017, p. 106), a partir de sua experiência clínica, elucida:

o que eu observo é que quando vamos com o paciente "tricotando" seus sonhos, ele vai abertamente nos trazendo suas associações. É como se o ego não se desse conta de que está nos prestando um serviço, está ficando à mostra. Vejo a resistência diminuída, e o que é importante, o paciente aceita, vindo dos sonhos, aspectos muito primitivos de seu psiquismo.

Os desafios lançados ao analista a tentar interpretar os sonhos são que: 0 analista não deve fazer interpretações baseadas na sua própria associação acerca do relato do sonho do paciente e "na ausência de associações do paciente, se o analista ficar na posição de analisar somente o conteúdo manifesto, embarca em interpretações provavelmente errôneas e superficiais" (Foster, 2017, p. 106). Freud, acerca dos desafios da interpretação dos sonhos, diz que:

não se deve esquecer que, ao interpretar um sonho, temos como oponentes as forças psíquicas que foram responsáveis pela sua deformação. Dessa maneira, é uma questão de força relativa saber se nosso interesse intelectual, nossa capacidade de autodisciplina, nosso conhecimento psicológico e nossa prática de interpretar sonhos capacitam-nos a dominar nossas resistências internas (Freud, 2017, p. 559 apud Foster, 2017, p. 106).

Na perspectiva de Zimerman (2008, p. 423) atualmente 0 analista está mais atento às razões que levam os seus pacientes a terem determinados sonhos e busca as conexões que interligam diversos sonhos em uma mesma noite, por exemplo. Diz ainda que:

0 analista deve permanecer atento a como a mente do analisando está tentando encontrar soluções, integrar, gerar novos significados, enfim, elaborar as necessidades, desejos, demandas e conflitos que sob forma de lembranças já estavam representadas no ego, de longa data, e que, agora, reativadas por "restos diurnos", como não puderam ser colocadas em palavras, se expressam por meio da primitiva linguagem por meio de imagens, e associações visuais, à espera que 0 analista consiga traduzir seus sentimentos em uma linguagem verbal (Zimerman, 2008, p. 423).

Sobre a interpretação dos sonhos, "na época pioneira da interpretação dos sonhos, de fato, Freud dedicava uma atenção especial em cada detalhe, e a detalhes do detalhe de cada sonho" (Zimerman, 2008, p. 426), pois ele priorizava o papel da investigação dentro da psicanálise, além disso "partia do princípio de que a psicanálise deveria se comportar como um trabalho arqueológico, (...) para se atingir as repressões que jaziam no fundo do inconsciente" (Zimerman, 2008, p. 426). 0 que acontece atualmente, segundo 0 autor, é que o sonho é visto pelos analistas como um todo, um apanhado de informações que pretendem se comunicar com a consciência,"0 analista está mais atento ao "todo"de um determinado contexto atual do que às descobertas das repressões do passado" (Zimerman, 2008, p. 426).

Zimerman (2008, p. 428) enfoca que 0 analista não precisa examinar um sonho minuciosamente, levando meses para concluir uma interpretação. Afirma que mais importante que isso é"0 analista conseguir fazer o encadeamento de significados entre os inúmeros sonhos parciais que, muito comumente, foram sonhados em uma mesma noite". Traz que o objetivo do analista então é o de "poder fazer uma integração, uma síntese e a descoberta de um "denominador comum", entre alguns dos elementos que estejam presentes nos diversos fragmentos de todos os sonhos relatados" (Zimerman, 2008, p. 428). 0 autor traz a metáfora de que"em uma floresta, mais importante do que examinar árvore por árvore, se observa a floresta como um todo" (Zimerman, 2008, p. 428). Sendo assim, é essencial que o analista consiga fazer um retrato de todo o conjunto de sonhos relatados pelo paciente e seja capaz de produzir uma história do seu passado, conectando com o momento atual da dinâmica do seu psiquismo em relação ao seu processo psicoterápico.

É imprescindível que 0 analista, a fazer a escuta de um sonho, mantenha o seu estado mental, sugerido por Bion: "sem memória, sem desejo e sem ânsia de compreensão imediata" (Zimerman, 2008, p. 428), o que enfatiza que 0 analista não deve estar com a sua mente preparada com conceitos 
prévios ansiando em fazer uma interpretação. Segundo Zimerman (2008, p. 429) "essa condição mental despojada, junto com uma escuta interessada e voltada para uma integração dos múltiplos pedaços do "quebra-cabeças" que o sonho despertou, é que vai possibilitar que 0 analista "sonhe a sessão".

0 analista deve evitar ficar na posição de quem é detentor de todo o saber e alimentar essa fantasia do seu paciente, que imagina que o analista sabe e pode interpretar todas as coisas do inconsciente. Sendo assim, "cabe ao analista incentivar que o paciente transmita as suas impressões acerca de seu sonho, que faça o exercício de associação de ideias, sentimentos e imagens, independentemente se elas estarão corretas, ou não" (Zimerman, 2008, p. 429).

Outro aspecto apontado pelo autor diz respeito à questão de ser o sonho a"via régia" para 0 inconsciente, que atualmente não é mais percebida com essa perspectiva absoluta, pois:

existem inúmeras outras vias que conduzem ao inconsciente, como são as múltiplas modalidades de "comunicações não-verbais", como actings, somatizações, surgimento espontâneo de ideogramas, narrativas de filmes, livros, com a respectiva identificação do paciente com certos personagens, etc. (Zimerman, 2008, p. 422).

0 estudo freudiano dos sonhos revela o inconsciente como o estrangeiro-em-mim- mesmo, desterra então o sujeito do controle, de ser senhor de si. "Pela brecha aberta pelos sintomas, chistes, atos-falhos e sonhos adentra-se um invisível que, mais do que trazer à luz elementos até então desconhecidos, produz - no processo mesmo de análise - um radical rearranjo dos sentidos" (Gurfinkel, 2008, p. 140).

Pontalis (1978, como citado por Gurfinkel, 2008, p. 124) ressalta que o processo do sonho não pode funcionar segundo a sua lógica própria, se 0 sistema psíquico (espaço do sonho) não tiver se constituído enquanto tal. 0 autor comparou o processo onírico com um filme ou peça de teatro: "sem película não há filme, e não há peça teatral sem cenário. Também o sonho pressupõe um espaço onde possa se dar uma representação".

Bollas (1987, como citado por Gurfinkel, 2008, p. 125) "concebeu 0 espaço de sonho como um teatro noturno, e ressaltou que a contribuição fundamental do sonho para a sensibilidade humana foi sua oferta de um espaço para a interação do self com o Outro."

Pontalis (1978, como citado por Gurfinkel, 2008, p. 147) entende que a percepção no sonho pode ser tomada como modelo de toda a percepção, já que no sonho se dá uma alucinação real, verdadeira, que tem como característica a realização de um desejo. No sonho, segundo o autor, "a percepção é mais percepção do que toda percepção da vigília".

Tendo em vista o caráter alucinatório dos sonhos, al gumas más interpretações podem vir a acontecer. 0 que é verdade para o sujeito nunca deve ser confundido com a correção do processo alheio a ele, que media a relação entre o Eu com a realidade exterior social e compartilhada. A psicanálise contribui para a maneira correta de interpretar os sonhos através do conceito acerca do inconsciente, dessa "realidade psíquica" que "deve ser distinguida da falsidade e do oportunismo de um Eu mediador, forjado por mimetismo do meio ambiente. Daí a alucinação verdadeira do sonho" (Gurfinkel, 2008, p. 148).

Na filosofia, o sonho é interpretado como um"produto imaginário: uma imagem projetada na superfície plana de uma tela interior, que simplesmente espelha e redobra a unidade identitária (SEGUE TRECHO DO LIVRO) do sonhador" (Gurfinkel, 2008, p. 148). Por outro lado, simultâneo a esse procedimento do imaginário, no sonhar é possível perceber um furo nos estados de consciência que desarticula a identidade do sujeito.

Freud, ao descobrir no sonho um impulso inconsciente que descentra o sujeito da visão de mundo construída por seu Eu unitário, reinstaura um olhar que, através das brechas de um mundo até então fechado e plano, a imagem do sonho "produz uma diferenciação no interior do próprio mundo e, por decorrência, um efeito de estranhamento. E ainda: o retorno a um "estado de ovo" da regressão do sono é também um reencontro com o núcleo do si-mesmo" (Gurfinkel, 2008, p. 148-149). Isso possibilita ao sujeito um reestabelecimento do potencial criativo e da capacidade de criar o mundo, proporciona a capacidade de ver tudo de uma maneira renovada, segundo Winnicott (1970, como citado por Gurfinkel, 2008, p. 149). A "travessia da análise e a experiência do sono-sonho implicam sempre, pois, a "vertigem da desestruturação" (Gurfinkel, 2008, p. 149).

Perrini (2017) reflete sobre o sonho e o sonhar fora e dentro da sessão analítica, destacando a presença forte do sonho na psicanálise, desde Freud e, por meio de exemplos clínicos, apresenta o sonho, o sonhar, o sonho-a-dois, o sonho noturno e o sonho diurno como importantes fatores de comunicação entre analista e analisando. 0 autor propõe que:

Somente com base em mudanças internas faz sentido observar a transformação do "analista intérprete", como está em "A interpretação dos sonhos" (Freud, 1933, p. 376), para o analista que "contracena" com os elementos que brotam na sessão, no sonho, na fala, em tudo aquilo que vamos sentindo no contato com o analisando: o que emerge no devaneio do analista (Perrini, 2017, p. 69).

Nessa perspectiva, "0 sonho do paciente mostra cenas que constituem um enredo ou história que estimulará 0 analista a contracenar no campo analítico" (Cassorla, 2009 citado por Perrini, 2017, p. 69).

0 autor enfatiza que a riqueza conceitual descoberta por Freud fica preservada:

o sonho como realização de um desejo, a presença da busca mental de representação, os movimentos acionados pela condensação, pelo deslocamento, a procura da simbolização, o caminho entre 0 pensamento onírico latente e o que realmente pode ser expresso, os meandros que percorrem os afetos nos sonhos (Perrini, 2017, p. 70).

Susemihl (2017) inicia com a retomada do texto fundante da psicanálise, a obra magna, comentando algo da história de sua escrita e apresentando um resumo das ideias principais de Freud sobre o processo onírico. Busca em alguns autores as ideias próprias sobre sonhos, sonhar e trabalho clínico com sonhos, tentando reconhecer uma invariância com as proposições freudianas, bem como extensões e desenvolvimentos. 0 texto é permeado por vinhetas clínicas, que visam ilustrar algo do que está sendo apresentado.

Freud, em 1933 resume pontos fundamentais e al gumas novas reflexões acerca dos sonhos e denomina como "Revisão da teoria dos sonhos". Na visão de 
Susemihl (2017, p. 114)"ao término da leitura não nos parece que houve al guma revisão importante. A esperada revisão à luz das novas teorias (...) não foi além das notas já introduzidas ao longo das edições do próprio livro dos sonhos".

Freud deixa-nos então um último resumo do que ele determinou como as características básicas do seu estudo dos sonhos. A autora Susemihl (2017, p. 115) levanta alguns pontos principais desse resumo, como por exemplo: o sonho é composto por um conteúdo manifesto e um conteúdo latente, 0 sonho serve como uma espécie de manutenção do sono, podendo ser usado para investigação da psique de quem sonha. Durante o estado de sono se estabelece um relaxamento das repressões e da censura, sendo assim, os impulsos inconscientes profundamente recalcados emergem, se aliam aos pensamentos latentes pré-conscientes e produz o sonho, se apresentando como desejos satisfeitos.

Melanie Klein possui uma relação diferente com os sonhos dos pacientes e Susemihl (2017, p. 118) diz que:"Klein não parece interessada na questão da realização do desejo, ou na função do sonho, ainda que possamos reconhecer esses elementos nas entrelinhas e nos sonhos". Klein se afastou das concepções de Freud e construiu uma maneira própria de utilizar e interpretar os sonhos dos seus pacientes. Através das brincadeiras com as crianças que atendia, foi se aproximando do conteúdo latente dos sonhos que apareciam "com base nos símbolos que se referem às angústias inconscientes, e que estão relacionadas com o que está posto na vida atual." (Susemihl, 2017, p. 119). Klein nos mostra que "o sonho pode ser utilizado em sua qualidade expressiva como comunicação pessoal e interpessoal, quando existe alguém para apreender seu sentido." (Susemihl, 2017, p. 119).

Por fim, o estudo de Solms (como citado por Cheniaux, 2006, p. 173) trouxe uma perspectiva da neurociência para a teoria dos sonhos. 0 autor refere que "0 envolvimento na geração dos sonhos do sistema mesolímbico-mesocortical, claramente relacionado ao que a psicanálise chama de pulsões, parece confirmar a afirmativa de Freud quanto a um desejo ser o instigador do sonho". Diversos autores concordam que "os sonhos são de grande importância para a elaboração de traumas e conflitos psíquicos e têm um papel terapêutico, semelhante ao da psicoterapia" (Cheniaux, 2006, p. 174). A neurociência trouxe um modelo para explicar o processo de elaboração do trauma nos sonhos. Nos sonhos, acredita-se que as redes neurais se comuniquem com maior facilidade, entretanto, "essas conexões não são feitas de forma aleatória: as emoções seriam os organizadores das redes neurais"(Cheniaux, 2006, p. 174).

Podemos dizer que as representações nos sonhos tendem a se associar a outras que tenham o mesmo sentido afetivo. Com isso, segundo 0 autor, a lembrança de um trauma consegue se associar a outras memórias, e assim, se tornar menos perturbadora.

\section{Considerações finais}

Este estudo buscou compreender o mundo onírico, a fim de enfatizar a sua importância no processo terapêutico, a partir de Freud e de estudos atuais. A partir da revisão na base de dados, poucos artigos atuais foram encontrados, o que pode ser pensado como hipótese de que a destinação deste tipo de escrita se concentre a revistas especializadas em psicanálise. Os trabalhos encontrados retomam a obra Freudiana e trazem contribuições sobre o uso dos sonhos como dispositivo no processo terapêutico, por meio de revisão de literatura e de relato e discussão de casos.
A construção desse artigo se deu apoiada sobre importantes conceitos acerca da temática dos sonhos. Através desse trabalho, foi possível compreender que os sonhos são realizações de desejos e que mesmo os sonhos desagradáveis cumprem com esse propósito, o que foi esclarecido através de exemplos de sonhos particulares de Freud. Neste trabalho, observou-se o papel do analista frente aos relatos dos sonhos dos seus pacientes, que 0 mesmo deve ater-se a todos os relatos de sonhos, buscando encontrar uma conexão entre eles, a fim de conhecer os diferentes momentos da vida do seu paciente, para ser capaz de produzir uma história do seu passado, conectando com o momento atual da dinâmica do seu psiquismo em relação ao seu processo psicoterápico.

Em uma reflexão filosófica, percebemos que para sonhar, devemos ter um espaço psíquico em bom funcionamento. Para sonhar, é necessário se permitir sonhar, permitir que a mente crie e explore diferentes versões do ser, assim como o brincar, quando criança. Para a filosofia, então, o sonho pode ser explicado como uma imagem projetada na superfície plana de uma tela interior, que simplesmente espelha e redobra a unidade identitária do sonhador.

Foi possível relacionar também a visão neurocientífica à visão psicanalítica dos sonhos, apontando para a importância dos sonhos na elaboração de traumas e conflitos psíquicos e têm um papel comparável ao da psicoterapia, tendo em vista que nos sonhos as redes neurais se comunicam com maior facilidade, mas não o fazem de forma aleatória, o que organiza essas redes são as emoções.

Um dos aspectos a salientar desta breve revisão, é acerca da intuição psicanaliticamente treinada, como sendo produto da relação de duplas psicanalíticas, que "se revigora em nossa análise pessoal, em nosso trabalho de psicanalistas clínicos, nas experiências de supervisão, e em reuniões, jornadas ou seminários em que podemos trocar experiências e ratificar conceitos com base na clínica partilhada". (Perrini, 2017, p. 70).

\section{Referências}

Cheniaux, E. (2006). Os sonhos: integrando as visões psicanalítica e neurocientífica. Revista de Psiquiatria do Rio Grande do Sul, 28(2), 169- 177. doi. org/10.1590/s0101-81082006000200009.

Foster, M. (2017). Interpretação de sonhos e contemporaneidade: uma regra ainda fundamental. Jornal de Psicanálise, 50(93), 97-109., dehttp:// pepsic.bvsalud.org/scielo.php?script=sci_arttext\&pid=S010358352017000200007\&lng=pt\&tlng=pt.

Freud, S. (2017). A Interpretação dos sonhos. Trad.Renato Zwick. (11. ed), Porto Alegre, RS: L\&PM, 2017.

Gil, A. (2002). Como elaborar projetos de pesquisa. (4. ed). São Paulo: Editora Atlas.

Gurfinkel, D. (2008). Sonhar, dormir e psicanalisar: viagens ao informe. São Paulo: Escuta/Fapesp.

Perrini, E. A. L.. (2017). "Me alugo para sonhar": algumas ideias sobre sonhos e sonhar em psicanálise. Jornal de Psicanálise, 50(93), 67-78. http://pepsic.bvsalud.org/scielo.php?script=sci_arttext\&pid=S010358352017000200005\&lng=pt\&tlng=pt.

Rivera, T. (2017). 0 sonho e o século. In: Freud, S. (1933) A Interpretação dos sonhos. Trad. de Renato Zwick. (11.ed), Porto Alegre, RS: L\&PM, 2017.

Susemihl, E. V. K. P. (2017). Interpretação dos sonhos, sem fim. Jornal de Psicanálise, 50(93), 111-126. http://pepsic.bvsalud.org/scielo.php?scrip$t=s c i \_a r t t e x t \& p i d=S 0103-58352017000200008 \&$ Ing =pt\&tlng=pt.

Zimerman, David E. (2008). Manual de técnica psicanalítica. Porto Alegre: Artmed. 